\title{
Monetary policy effects on equity returns: application of SVAR identified with high-frequency external instrument
}

\author{
Woon Wook Jang \\ Division of Business Administration, Yonsei University, Wonju, Republic of Korea
}

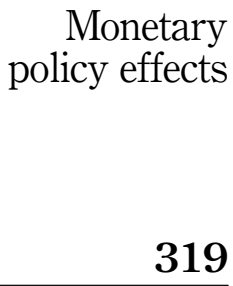

Received 10 August 2021 Revised 26 August 2021 Accepted 27 August 2021

\begin{abstract}
The purpose of this study is to examine the effects of monetary policy on equity returns by applying an alternative econometric approach. Campbell and Ammer (1993) decomposed unexpected equity excess returns into three news components: risk premium news, real interest rate news and cash-flow news. The literature has determined the monetary policy (MP) effects on these news components. The authors propose an alternative MP shock identification approach to analyze the MP effects on the above-mentioned news components under a structural vector autoregression (SVAR) setup. Under this approach, one can apply an MP indicator in the SVAR, which helps forecast equity excess returns along with its external instruments for identification. Further, this study uses the various recently proposed measures of exogenous MP shocks and Fed information shocks as external instruments, and shows the different patterns of the news components' responses depending on the information in the applied instruments.
\end{abstract}

Keywords Equity return decomposition, Monetary policy effects, Structural vector autoregression,

External instruments

Paper type Research paper

\section{Introduction}

An unexpected drop in equity excess returns may be attributed to a decline in expected future dividends, an increase in future real interest rates or an increase in future risk premium. To analyze the components that derive an unexpected change in the equity excess returns, Campbell and Ammer (1993) used a log-linear approximation and decomposed unexpected equity excess returns into the three news components (i.e. risk premium news, real interest rate news and cash-flow news components); they estimated the components using a vector autoregression (VAR) setup [1]. Building on this, Patelis (1997) and Bernanke and Kuttner (2005) analyzed the responses of the news components to monetary policy (MP) surprises. Specifically, Patelis (1997) used a structural VAR (SVAR) setup, wherein the endogenous state variables include MP indicator variables [2], and applied the Choleski decomposition (i.e. zero short-run restriction) to identify MP shocks. Alternatively, Bernanke and Kuttner (2005) assumed no MP indicators in the (endogenous) state variables in their reduced-form VAR model [3], but added an MP surprise measure as an exogenous variable. By doing so, Bernanke and Kuttner avoided the shock identification problem. However, this is tantamount to assuming that MP shock is purely exogenous to stock markets, and MP action is not contemporaneously affected by stock market information. Considering that stock prices

\section{JEL Classification - E44, E52, E58, G12}

(c) Woon Wook Jang. Published in Journal of Derivatives and Quantitative Studies: 선물연구. Published by Emerald Publishing Limited. This article is published under the Creative Commons Attribution (CCBY 4.0) licence. Anyone may reproduce, distribute, translate and create derivative works of this article (for both commercial and non-commercial purposes), subject to full attribution to the original publication and authors. The full terms of this licence maybe seen at http://creativecommons. org/licences/by/4.0/legalcode.

\section{.}


JDQS 29,4

320 move fast, reflecting market information, and that the Federal Reserve (hereafter, the Fed) also reflects financial markets information in its decision process, such an assumption is counterintuitive.

This study provides an alternative approach to analyzing the responses of unexpected equity excess return news components to MP shocks in an SVAR setup. Building on Patelis (1997), we use the SVAR approach and include an MP indicator variable in the state variable vector. However, we identify our SVAR using an external high-frequency MP instrument, rather than the Choleski decomposition in Patelis (1997). This identification allows us to not restrict the contemporaneous relation among the endogenous state variables, specifically the contemporaneous relation between excess stock returns and the MP indicator variable, unlike Bernanke and Kuttner (2005).

Econometrically, our shock identification approach is a novel application of the SVAR identification methodology of Mertens and Ravn (2013) applied to the study of MP effects on the unexpected equity excess return components of Campbell and Ammer (1993).

In the empirical analysis, as the MP indicator in the state variable vector, we use the effective Fed funds rate (FFR), shadow rate of Wu and Xia (2016) and another shadow rate of Krippner (2013), in turn. As an external instrument variable, we apply the high-frequency price change of the three-month ahead Fed fund futures (FF4) around Federal Open Market Committee (FOMC) announcements, converted into monthly values. We also apply two sets of its decomposition: one developed by Lakdawala and Schaffer (2019), and the other by Jarocinski and Karadi (2020). These studies considered that the central bank's actions not only convey its policy, but also demonstrate its assessment of the macroeconomic outlook, which is privately possessed by the Fed. Using different decomposition methodologies, Lakdawala and Schaffer (2019) and Jarocinski and Karadi (2020) decomposed the FF4 into a pure exogenous MP shock (EXO) and a Fed information shock (FIS). Therefore, with the decomposed shocks, we can study different stock market responses to different MP shock information.

The empirical results show that a contractionary pure exogenous MP shock decreases unexpected excess returns, driven mainly by the decreased cash-flow news component. By contrast, the Fed information shocks increase unexpected index returns, driven mainly by the decreased risk premium news components.

This study contributes to the literature by providing an approach that can include an MP indicator variable in the state variables of SVAR while identifying MP shocks using external instruments. Patelis (1997) also used an SVAR setup in his study of MP shock effects on equity returns, but he identified structural shocks using a strong assumption of the ordering of variables in the state vector. By contrast, we identified structural shock without assuming any ordering of the variables, which is possible by using external instruments.

Empirically, this study also contributes to current scholarship in its discovery of different responses of unexpected equity return components to different MP shocks: When the Fed conveys a purely contractionary shock (EXO), firms' cash flows are negatively affected. By contrast, while the markets interpret a positive outlook by the Fed to be beneficial for the macroeconomy, even though it appears as a contractionary policy (FIS), the markets lower the risk premium required by firms, and increase excess returns.

The remainder of this paper is as follows. Section 2 introduces the econometric methods of this study, Section 3 explains the data and shows the study's empirical results, and Section 4 offers concluding remarks.

\section{Econometric methodology}

We denote the log excess equity return at time $t$ as $y_{t}$ and its unexpected component at time $t+1$ as $e_{t+1}^{y}\left(=y_{t+1}-E_{t}\left[y_{t+1}\right]\right)$, which Campbell and Ammer (1993) decomposed into risk premium news $\left(N_{R P}\right)$, real interest rate news $\left(N_{R R}\right)$ and cash-flow news $\left(N_{C F}\right)$ as follows: 


$$
e_{t+1}^{y}=-N_{R P, t+1}-N_{R R, t+1}+N_{C F, t+1}
$$

where,

$$
\begin{aligned}
& N_{R P, t+1}=\left(E_{t+1}-E_{t}\right) \sum_{j=1}^{\infty} \rho^{j} y_{t+1+j}, \\
& N_{R R, t+1}=\left(E_{t+1}-E_{t}\right) \sum_{j=1}^{\infty} \rho^{j} r_{t+1+j},
\end{aligned}
$$

and

$$
N_{C F, t+1}=\left(E_{t+1}-E_{t}\right) \sum_{j=0}^{\infty} \rho^{j} \Delta d_{t+1+j} .
$$

Here, $d_{t}$ are the log dividends, $r_{t}$ is the $\log$ real interest rate and $\rho$ is a discount factor set to 0.9962 by convention in the literature (Campbell and Ammer, 1993; Bernanke and Kuttner, 2005). Campbell and Ammer (1993) estimated it using a VAR, where state variable vector $\tilde{Z}$ includes the log equity excess return, dividend-price ratio and the other variables that help forecast equity excess returns:

$$
\tilde{Z}_{t+1}=\tilde{A} \tilde{Z}_{t}+w_{t+1}
$$

where $\tilde{A}$ is a coefficient matrix, and $w_{t+1}$ is a vector of forecasting error.

\subsection{Bernanke and Kuttner's methodology}

Bernanke and Kuttner (2005) extended the VAR model to include an MP surprise variable $m_{t}$, which is exogenous to endogenous state variable $\tilde{Z}$ :

$$
\tilde{Z}_{t+1}=\tilde{A} \tilde{Z}_{t}+\phi m_{t+1}+\varepsilon_{t+1},
$$

where $\phi$ is a coefficient vector, and $\varepsilon_{t+1}$ is an error term. In Bernanke and Kuttner's (2005) approach, the MP shock $m_{t}$, is purely exogenous to the excess stock return $y_{t}$, in $\tilde{Z}$. Therefore, any MP action may affect stock return, but not vice-versa, contemporaneously.

Bernanke and Kuttner (2005) derived the responses of the three components to the MP surprise $m_{t}$, as follows:

$\tilde{R}_{e}=e_{y}^{\prime} \phi$ : response of the current excess returns to the MP surprise.

$\tilde{R}_{R P}=e_{y}^{\prime} \rho A(1-\rho A)^{-1} \phi$ : response of risk premium news to the MP surprise.

$\tilde{R}_{R R}=e_{r}^{\prime}(1-\rho A)^{-1} \phi$ : response of real rate news to the MP surprise.

$\tilde{R}_{C F}=\left(e_{y}^{\prime}+e_{r}^{\prime}\right)(1-\rho A)^{-1} \phi$ : response of cash-flow news to the MP surprise.

Here, $e_{y}$ and $e_{r}$ are selection vectors with the value of one at the position of relevant variable (excess return, $y_{t}$, and real rate, $r_{t}$, respectively), and zero otherwise.

\subsection{Structural vector autoregression identified with external instrument}

This study approaches it differently using an SVAR setup, following Patelis (1997). We assume that one of the state variables is an MP indicator, such as $z_{t}^{m}$, so that $Z_{t}=\left[\begin{array}{ll}z_{t}^{m} & Z_{t}^{o \prime}\end{array}\right]^{\prime}$, where $Z_{t}^{o}$ is the vector of the other state variables, including the log excess equity return and the dividend-price ratio. One may think of $Z_{t}^{o}$ as $\tilde{Z}_{t}$ in equation (1) or (2). The MP indicator variable, $z_{t}^{m}$, need not be the first element of $Z_{t}$ in our identification methodology; it is so only for expositional simplicity. We assume the dynamics of $Z_{t}$ as follows: 
JDQS

29,4

$$
B Z_{t+1}=C Z_{t}+u_{t+1} .
$$

where $B$ and $C$ are $n \times n$ coefficient matrices and $u_{t}$ is an $n \times 1$ vector of structural shocks with mean zero and unit variance matrix. Its reduced form representation is:

$$
Z_{t+1}=A Z_{t}+D u_{t+1},
$$

where $A=B^{-1} C$ and $D=B^{-1}$. Here, we define $e_{t}$ as the reduced form residual in equation (4), such as:

$$
e_{t}=D u_{t}
$$

and consider partitioning $e_{t}=\left[\begin{array}{ll}e_{t}^{m} & e_{t}^{o \prime}\end{array}\right]^{\prime}$, where $e_{t}^{m}$ is a reduced form shock of the MP indicator variable and $e_{t}^{o}$ is that of the other variables.

Patelis (1997) identified $D$ by applying the Choleski decomposition after assuming a specific ordering among the state variables. Specifically, he used six state variables and put the MP indicator variable (change in the FFR) first and excess stock returns last. This is assuming the MP indicator affects excess stock return contemporaneously, but not viceversa. Alternatively, we identify it using the methodology of Mertens and Ravn (2013). In this approach, we do not restrict any specific ordering among the state variables, and all variables in the state vector could affect the others contemporaneously.

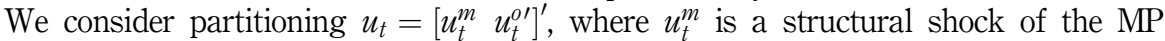
indicator variable and $u_{t}^{o}$ is that of the other variables. We also partition:

$$
D=\left[\begin{array}{ll}
D_{1} & D_{2}
\end{array}\right]=\left[\begin{array}{ll}
d_{11} & d_{12} \\
d_{21} & d_{22}
\end{array}\right],
$$

where $D_{1} \equiv\left[\begin{array}{ll}d_{11} & d_{21}^{\prime}\end{array}\right]^{\prime}$ and $D_{2} \equiv\left[\begin{array}{ll}d_{12} & d_{22}^{\prime}\end{array}\right]^{\prime}$ are coefficient matrices corresponding to the impacts on each element of reduced form residuals to the MP structural shock, $u_{t}^{m}$, and the other structural shocks, $u_{t}^{o}$, respectively. Here, $d_{11}$ and $d_{21}$ correspond to the impacts on each element of reduced form residuals, $e_{t}^{m}$ and $e_{t}^{o}$, of MP structural shocks, $u_{t}^{m}$.

As our purpose is to find responses of unexpected excess equity return components to MP shocks, we only need to identify $D_{1}$. The identification methodology of Mertens and Ravn (2013) uses external instrument variables correlated with the MP indicator variable. Their methodology is a two-stage least squares regression of the reduced form residuals of the state variables on the reduced form residuals of the MP indicator variable using instruments. For a detailed estimation procedure for $D_{1}$, readers may refer to Mertens and Ravn (2013). For its application to MP effects, see Gertler and Karadi (2015). Here, we explain the methodology briefly.

We introduce an external instrument variable, $v_{t}$, correlated with MP structural shocks, $u_{t}^{m}$, but orthogonal to the other shocks, $u_{t}^{o}$, as follows:

$$
E\left[v_{t} u_{t}^{m}\right]=\psi, \quad E\left[v_{t} u_{t}^{o \prime}\right]=0,
$$

where $\psi$ is an unknown vector, and 0 is a zero vector. We define notations $\Sigma_{v e^{m}}=E\left[v_{t} e_{t}^{m \prime}\right]$ and $\Sigma_{v e^{o}}=E\left[v_{t} e_{t}^{o \prime}\right]$. In addition, we define the reduced-form covariance matrix $\Sigma \equiv E\left[e_{t} e_{t}^{\prime}\right]=D D^{\prime}$, and partition it as:

$$
\Sigma=\left[\begin{array}{cc}
\Sigma_{11} & \Sigma_{12} \\
\Sigma_{21} & \Sigma_{22}
\end{array}\right]
$$

here, $\Sigma_{11} \equiv \operatorname{Cov}\left[e_{t}^{m}, e_{t}^{m}\right], \Sigma_{21}=\Sigma_{21}{ }^{\prime} \equiv \operatorname{Cov}\left[e_{t}^{m}, e_{t}^{o}\right]=\Sigma_{12}=\Sigma_{12}{ }^{\prime}$ and $\Sigma_{22} \equiv \operatorname{Cov}\left[e_{t}^{o}, e_{t}^{o}\right]$. 
Then, we apply Mertens and Ravn's (2013) formula to find the matrix $D_{1}$. They defined a matrix $S$ as a squared form:

$$
S S^{\prime}=(I-L G) J(I-L G)^{\prime}
$$

Monetary policy effects

where $I$ is an identity matrix, and $L=\left\{H G^{\prime}+\left(\Sigma_{21}-G \Sigma_{11}\right)^{\prime}\right\} K^{-1}, \quad G=\left(\Sigma_{v e^{m}}\right)^{-1}\left(\Sigma_{z v e^{o}}\right)$, and where $K=\Sigma_{22}+G\left(H-\Sigma_{11}\right) G^{\prime}, H=\left(\Sigma_{21}-G \Sigma_{11}\right)^{\prime} Z^{-1}\left(\Sigma_{21}-G \Sigma_{11}\right)$ and $Z=G \Sigma_{11}$ $G^{\prime}-\Sigma_{21} G^{\prime}-G \Sigma_{21}^{\prime}+\Sigma_{22}$.

They assumed $S$ to be a triangular matrix and solved it to obtain the components $d_{11}$ and $d_{21}$ of $D_{1}$ as follows:

$$
d_{11}=(I-L G)^{-1} S \quad \text { and } \quad d_{21}=G d_{11}
$$

Given $D_{1}$, finding responses to the MP structural shocks is straightforward, whose formulas are very similar to those of Bernanke and Kuttner (2005), where the only difference is that $\phi$ is replaced by $D_{1}$ :

$$
\begin{aligned}
& R_{e}=e_{\mathrm{y}}^{\prime} D_{1} \text { : response of the current excess returns to the MP structural shock; } \\
& R_{R P}=e_{\mathrm{y}}^{\prime} \rho A(1-\rho A)^{-1} D_{1} \text { : response of RP news to the MP structural shock; } \\
& R_{R R}=e_{\mathrm{r}}^{\prime}(1-\rho A)^{-1} D_{1} \text { : response of RR news to the MP structural shock; and } \\
& R_{C F}=\left(e_{\mathrm{y}}^{\prime}+e_{\mathrm{r}}^{\prime}\right)(1-\rho A)^{-1} D_{1} \text { : response of CF news to the MP structural shock. }
\end{aligned}
$$

\section{Data and empirical applications}

Following Campbell and Ammer (1993) and Bernanke and Kuttner (2005), we use six state variables as $Z_{t}^{o}$ : CRSP equity excess return, real rate of interest, treasury-bill rate changes, dividend-price ratio, term spread between the ten-year and one-month treasury yields, and relative bill rate. We use the dataset of Lakdawala and Schaffer (2019), which includes all six variables from January 1991 to December 2011.

This study adds an MP indicator $\left(z_{t}^{m}\right)$ as the seventh state variable. Patelis (1997), Goto and Valkanov (2002), and Maio (2013) reported on the forecasting ability of the FFR for equity excess returns; therefore, as MP indicators among others, we apply the effective FFR. The effective FFR is the interest rate determined by the Fed funds market, which is influenced by

\begin{tabular}{lrrrccrrrr}
\hline & excessR & realR & \multicolumn{1}{c}{$\Delta$ TBill } & termS & dp & r.bill & $\Delta$ eFFR & $\Delta$ SR $_{\mathrm{Wx}}$ & $\Delta \mathrm{SR}_{\mathrm{KR}}$ \\
\hline Mean & 0.5725 & 0.6433 & -0.0263 & 2.1215 & 2.0412 & -0.1859 & -0.0299 & -0.0367 & -0.0481 \\
SE & 0.2824 & 0.2244 & 0.0184 & 0.0841 & 0.0390 & 0.0519 & 0.0364 & 0.0128 & 0.0239 \\
Median & 1.0343 & 1.0190 & -0.0051 & 2.2994 & 1.8362 & -0.0811 & -0.0100 & 0.0000 & -0.0400 \\
Std & 4.4921 & 3.5701 & 0.2928 & 1.3376 & 0.6208 & 0.8253 & 0.5797 & 0.2044 & 0.3799 \\
Var. & 20.1787 & 12.7453 & 0.0858 & 1.7892 & 0.3854 & 0.6811 & 0.3361 & 0.0418 & 0.1443 \\
Kurtosis & 1.4886 & 3.3170 & 2.6650 & -1.1415 & -0.5598 & 0.1418 & 3.6186 & 2.8339 & 0.9054 \\
Skewness & -0.7201 & 0.4522 & -0.5959 & -0.2593 & 0.6306 & -0.4392 & 0.0042 & -0.9964 & -0.3458 \\
Min & -18.5403 & -9.6038 & -1.1931 & -0.7034 & 1.1085 & -2.6581 & -2.0800 & -0.9600 & -1.3300 \\
Max & 11.3982 & 19.6387 & 0.9811 & 4.6268 & 3.7195 & 1.5851 & 2.6500 & 0.5300 & 0.9400 \\
$N$ & 253 & 253 & 253 & 253 & 253 & 253 & 253 & 253 & 253
\end{tabular}

Note(s): The table reports descriptive statistics for the state variable vector $Z_{t}$ in equations (3) and (4). The state variable vector includes CRSP equity excess return (excessR), real rate of interest (realR), treasury-bill rate changes ( $\Delta$ Tbill), dividend-price ratio (dp), term spread between the ten-year and one-month treasury yields (termS), and relative bill rate (r.bill). The seventh state variable is the MP indicator variable, to which we apply three variables in turns: change in the effective FFR $(\Delta \mathrm{eFFR})$, change in the shadow rate of Wu and Xia (2016, $\left.\Delta \mathrm{SR}_{\mathrm{WX}}\right)$ and change in the shadow rate of Krippner $\left(2013, \Delta \mathrm{SR}_{\mathrm{KR}}\right)$

Table 1. Descriptive statistics 
JDQS

29,4

324

Figure 1.

External MP

instruments

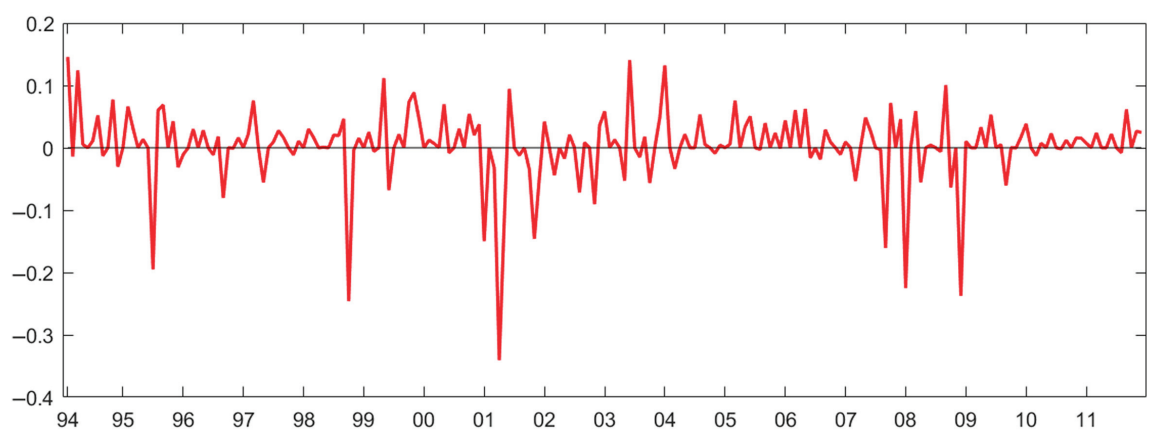

MP instrument: FF4

(a)

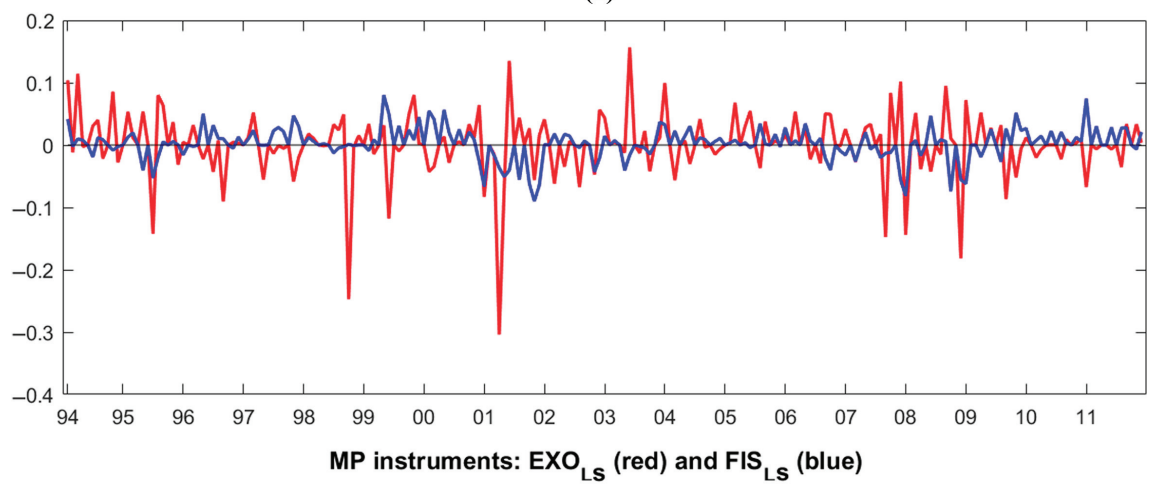

(b)

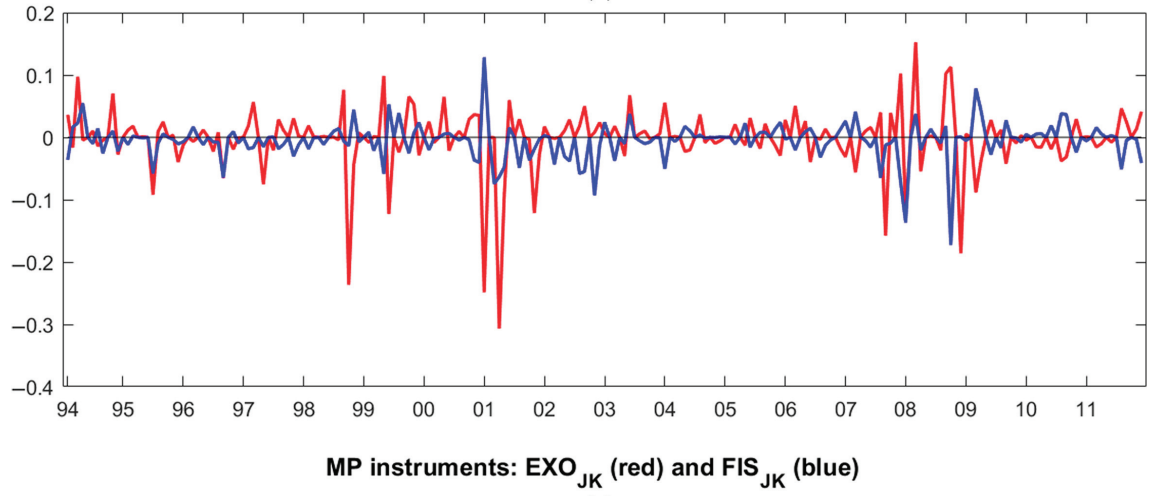

(c)

Note(s): The figures plot five MP instruments. FF4 is the high-frequency price change of the three-month ahead Fed fund futures around FOMC announcements. EXOLS and FIS $S_{L S}$ $\left(E X O_{J K}\right.$ and $\left.F I S_{J K}\right)$ are its decomposition into exogenous monetary policy shock and Fed information shock by Lakdawala and Schaffer (2019), respectively (Jarocinski and Karadi, 2020) 
the MP actions of the Fed. It is available in the Federal Reserve Economic Data (FRED, https:// fred.stlouisfed.org).

We also apply two extensions of FFR. The first is the shadow short rate of Wu and Xia (2016), and the other is the shadow rate of Krippner (2013). We consider shadow rates because we cover an early part of the recent crisis period, where policy rates were stuck by the zero lower bound, whereas shadow rates are not confined to positive values. Black (1995) provided the concept of a "shadow short rate" that could have both positive and negative values, while the nominal short rate is determined by the largest value between the shadow short rate and zero. Building on this concept, Black (1995) provided an interest rate model; however, this model has limited tractability. Recently, Wu and Xia (2016) and Krippner (2013) extended Black's (1995) model and developed more tractable shadow rate term structure models. The shadow short rate by Wu and Xia (2016) is available on Cynthia Wu's webpage [4], and that by Krippner (2013) is available from the Reserve Bank of New Zealand [5]. We use monthly changes for each indicator variable. Table 1 shows the descriptive statistics of endogenous variables.

We use monthly values for the excess return, and all other variables are annualized. For example, during our sample period, the mean of the monthly excess return was $0.57 \%$ points, while the level of the annual real interest rate was $0.64 \%$ points. The last three columns of Table 1 show the changes in MP indicator variables. Since the FFR was stuck at zero starting in December 2008, the change in the effective FFR (-0.0299) was smaller than the other shadow rates $(-0.0367$ for $\mathrm{Wu}$ and Xia's rate and -0.0481 for Krippner's rate).

To identify MP structural shocks, we use external MP instruments, $v_{t}$. We use measures of the various MP shocks, according to Lakdawala and Schaffer (2019, LS) and Jarocinski and Karadi (2020, JK). LS and JK used 30-min window price changes of the three-month Fed funds futures contracts around FOMC announcements. Specifically, they used the changes in the implied interest rate of the futures contracts around FOMC announcements, i.e. the FF4. LS decomposed theFF4 into FIS $S_{L S}$ and $E X O_{L S}$. They regressed the FF4 on the measure of the Fed's private information (measured as the difference between the Greenbook forecasts produced by the Fed and the consensus forecasts from the market-based Blue Chip survey). The fitted value of the regression is defined as $F I S_{L S}$. The residual of the regression is defined as the $E X O_{L S}$, which is a clean measure of an exogenous MP shock. JK also decomposed the FF4 into $F I S_{J K}$ and $E X O_{I K}$ by applying sign restrictions in their Bayesian SVAR setup. The identification of an MP shock was based on co-movement of interest rates and stock prices around FOMC announcements. Specifically, they identified a Fed information shock if two values change with the same signs. Otherwise, it was identified as an exogenous shock. In total, we use five external MP instruments in the empirical applications: FF4, EXO $O_{L S}, F I S_{L S}, E X O_{J K}$ and $F I S_{I K}$.

Decomposed data from Lakdawala and Schaffer (2019) are available from the Aeimit Lakdawala's webpage [6], while those of Jarocinski and Karadi (2020) are attached to the

\begin{tabular}{lllllc}
\hline & $F F 4$ & $E X O_{L S}$ & $F I S_{L S}$ & $E X O_{J K}$ & $F I S_{J K}$ \\
\hline$F F 4$ & 1 & & & & \\
$E X O_{L S}$ & $0.90^{* * *}$ & 1 & & & \\
$F I S_{L S}$ & $0.47 * * *$ & 0.03 & 1 & & \\
$E X O_{J K}$ & $0.83^{* * *}$ & $0.79^{* * *}$ & $0.30^{* * *}$ & 1 & 1 \\
$F I S_{J K}$ & $0.32^{* * *}$ & $0.22^{* * *}$ & $0.27 * * *$ & 0.02 & 1
\end{tabular}

Note(s): The table reports correlation coefficients among the five external MP instruments. FF4 is the highfrequency price change of the three-month ahead Fed fund futures around FOMC announcements. $E X O_{L S}$ and FIS $S_{L S}\left(E X O_{J K}\right.$ and $\left.F I S_{J K}\right)$ are its decomposition into exogenous MP shock and Fed information shock by Lakdawala and Schaffer (2019), respectively (Jarocinski and Karadi, 2020). *** denotes significance at

\footnotetext{
the $1 \%$ levels

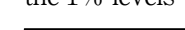


JDQS

29,4

326

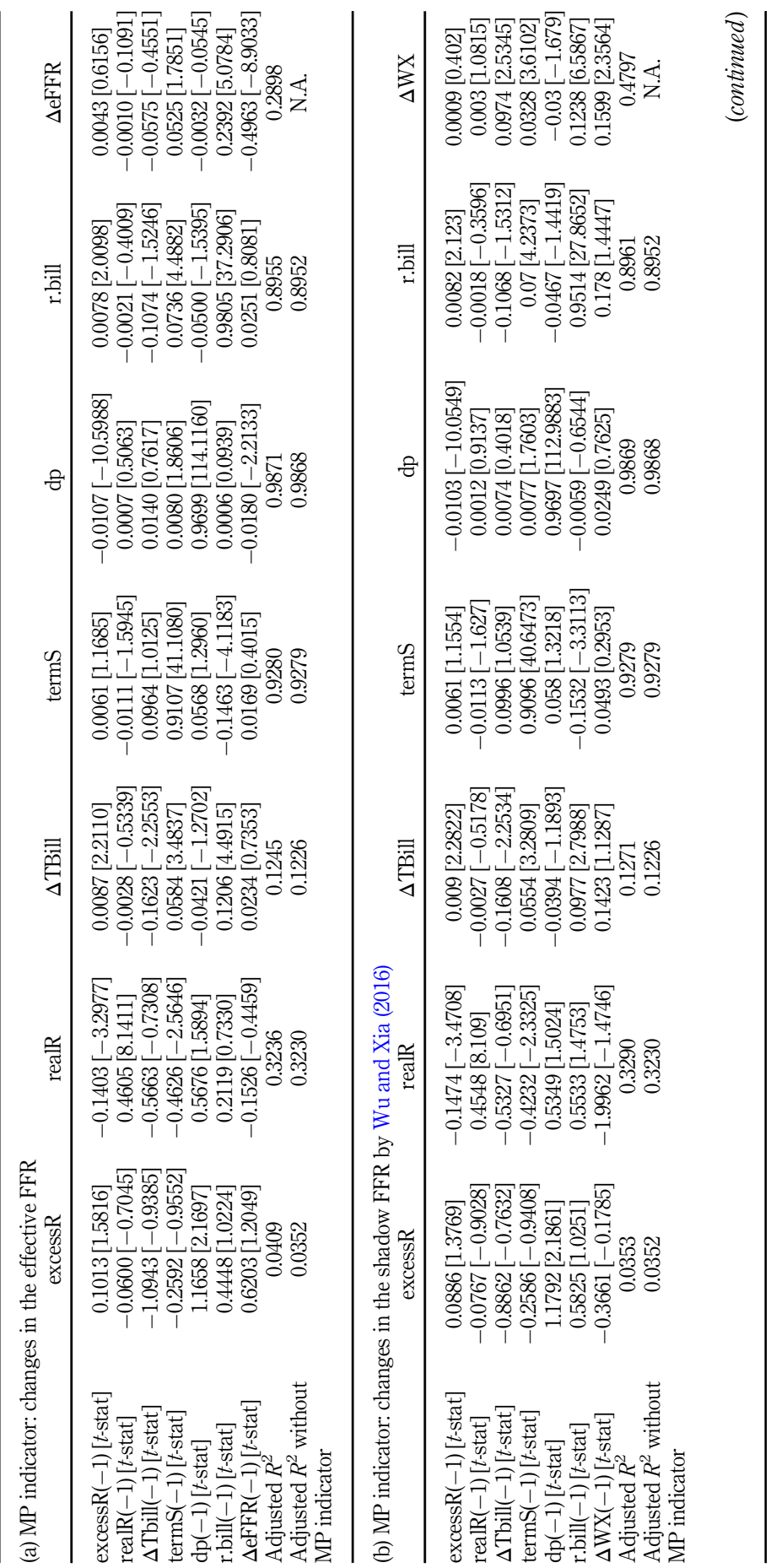

Table 3.

Estimated coefficient matrix of VAR

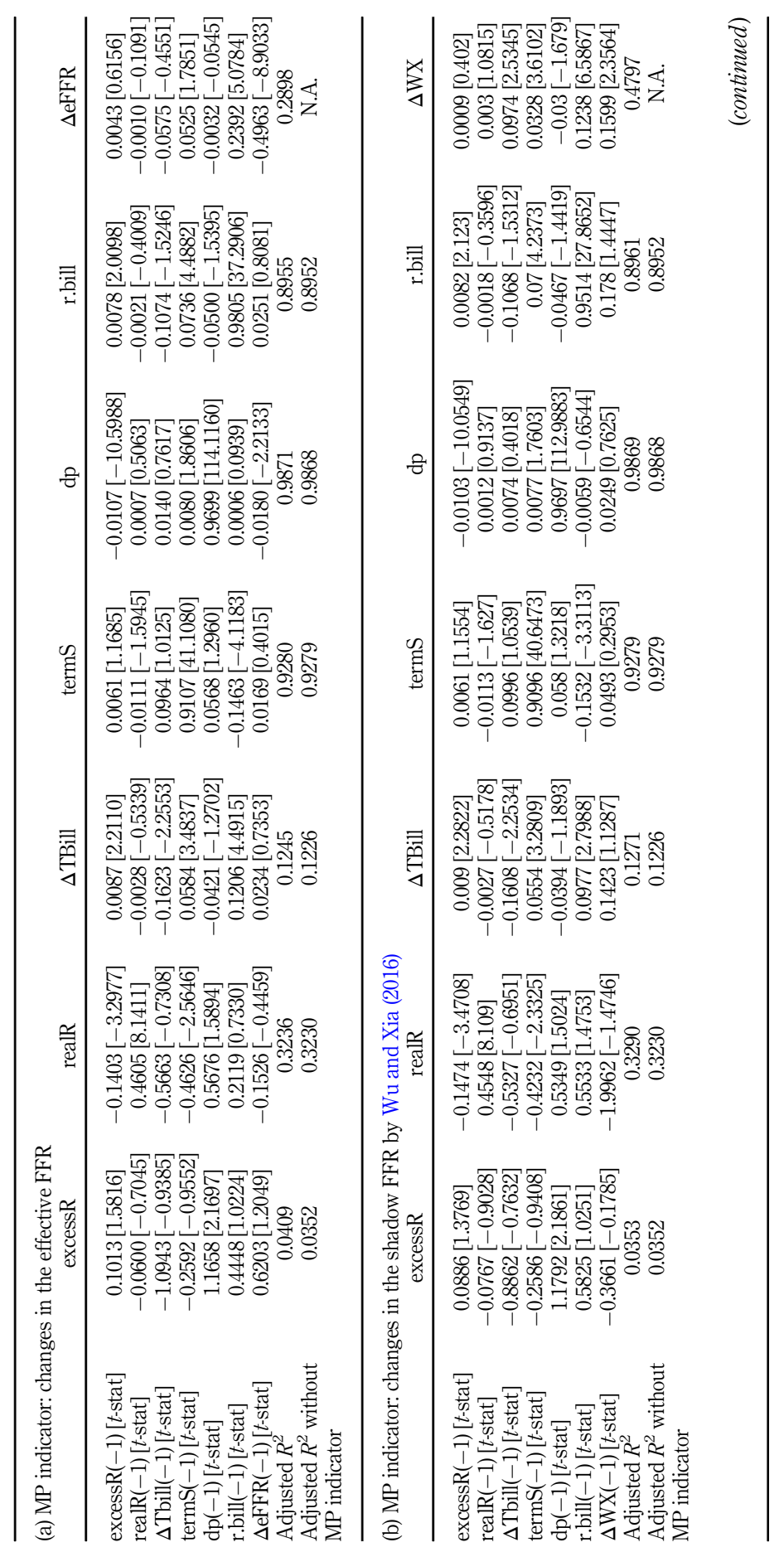




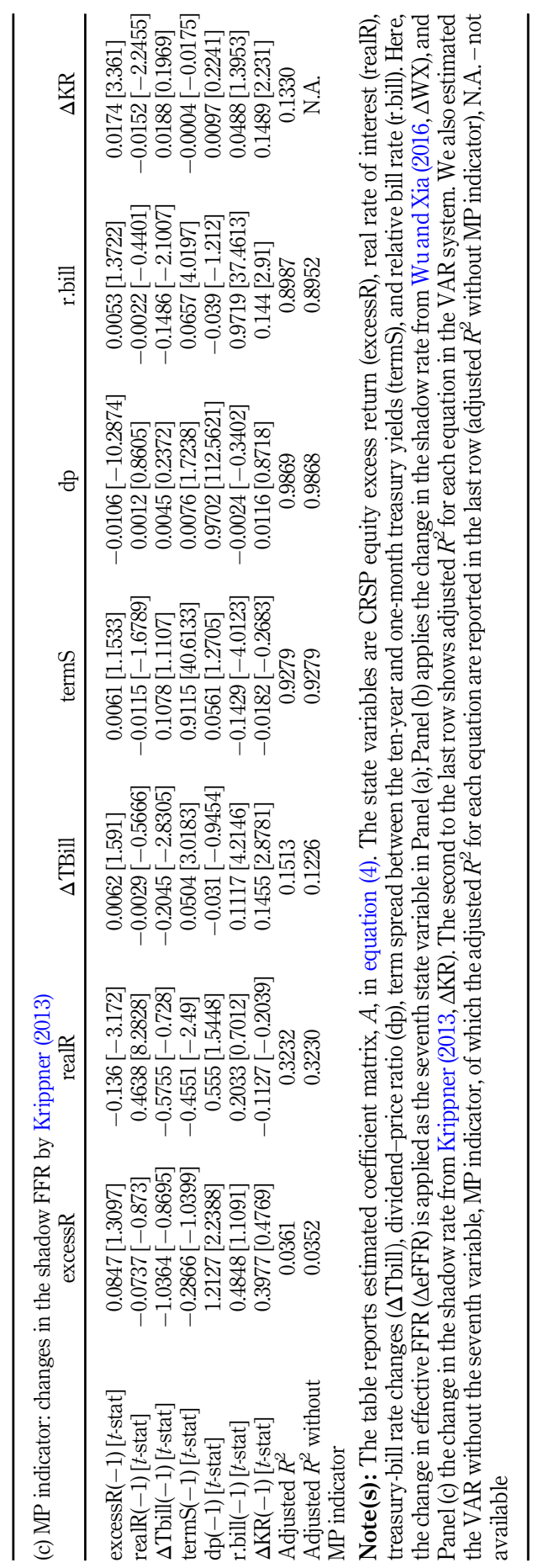

Monetary policy effects

327

Table 3. 
JDQS 29,4

\section{8}

paper appendix [7]. Figure 1 plots these five instruments, and Table 2 reports the correlation coefficient between them. We now notice that the $F F 4$ and exogenous MP shocks $\left(E X O_{L S}\right.$ and $\left.E X O_{J K}\right)$ are highly correlated, while the two Fed information shocks $\left(F I S_{L S}\right.$ and $\left.F I S_{J K}\right)$ are not, meaning that FISs have different information to the EXOs.

We then estimate the reduced form VAR in equation (4), and Table 3 reports the estimated coefficient matrix, $\widehat{A}$, with adjusted $R$-squared values for each equation in the VAR system. To compare the difference when there is no MP indicator in the VAR state vector, similar to Bernanke and Kuttner (2005), we also estimated the VAR without the MP indicator variable (resulting in total six variables in the state vector). When including the MP indicator (here, the change in the FFR), we obtain a higher adjusted $R^{2}$. Specifically, $R^{2}$ without the MP indicator is 0.0352 , while that with MP indicator is 0.0409. This validates our inclusion of MP indicators, which have predictive power for the equity excess return.

From the estimated coefficient matrix, $\widehat{A}$, we can calculate Campbell and Ammer's (1993) decomposed components of unexpected equity excess returns. Table 4 reports the variance decomposition of current unexpected excess equity returns into the variance of revisions in risk premium news (RP news), real interest rate news (RR news), cash-flow news (CF news) and the covariances between them. The innovation of the $\mathrm{CF}$ news and RP news explain about 39 and $34 \%$ of the fluctuation of current unexpected excess equity returns, respectively. However, which component does a policy change affect the most? This is another empirical question.

Table 5 reports the responses of unexpected equity excess return components to contractionary MP shocks. Panel (a) shows the results when using the effective FFR as an MP indicator. Each column shows the responses of the excess return, RP, RR and CF news components to one unit of structural shock (i.e. contractionary shock) of the MP indicator, $u_{t}^{m}$, identified using different external MP instruments ( $F F 4, E X O_{L S}, E X O_{J K}, F I S_{L S}$ and $\left.F I S_{J K}\right)$. Standard errors are between parentheses, calculated by 10,000 times of bootstrapping.

When we apply the $F F 4$ as an external instrument, the MP shock decreases the unexpected excess returns, which, in turn, is driven by the decreased $\mathrm{CF}$ and the increased RP and RR. Here, the magnitude of the $\mathrm{CF}$ is largest, followed by the RP, whereas that of the RR is smallest.

The other four columns show the results when applying the decomposed MP shocks as an instrument. Interestingly, for purely exogenous instruments $\left(E X O_{L S}\right.$ and $\left.E X O_{J K}\right)$, the results are very similar to that of $F F 4$ : the response of the $\mathrm{CF}$ is largest and statistically significant. Meanwhile, when Fed information shocks $\left(F I S_{L S}\right.$ and $\left.F I S_{J K}\right)$ are applied, the excess returns increase, driven mainly by the reduced RP. These patterns are similar when we apply the different MP indicators in Panels (b) and (c) of Table 5.

We can interpret the results as follows: a pure contractionary MP shock decreases unexpected equity excess returns, and which is driven by affecting firm's cash flow

\begin{tabular}{lrr}
\hline & Total & Share $(\%)$ \\
\hline $\operatorname{Var}($ Excess return) & 19.4187 & \\
$\operatorname{Var}($ RP news) & 6.6101 & 34.04 \\
$\operatorname{Var}($ RR news) & 0.2705 & 1.39 \\
$\operatorname{Var}(\mathrm{CF}$ news) & 7.5716 & 38.99 \\
-2 Cov(CF,RP) & 4.6199 & 23.79 \\
-2 Cov(CF,RR) & 0.2974 & 1.53 \\
+2 Cov(RP,RR) & 0.0491 & 0.25
\end{tabular}

Table 4.

Variance decomposition

Note(s): The table shows the variance decomposition of current unexpected excess equity returns (excess return) into the variance of revisions in risk premium news (RP news), real interest rate news (RR news), cashflow news (CF news) and the covariances between them 


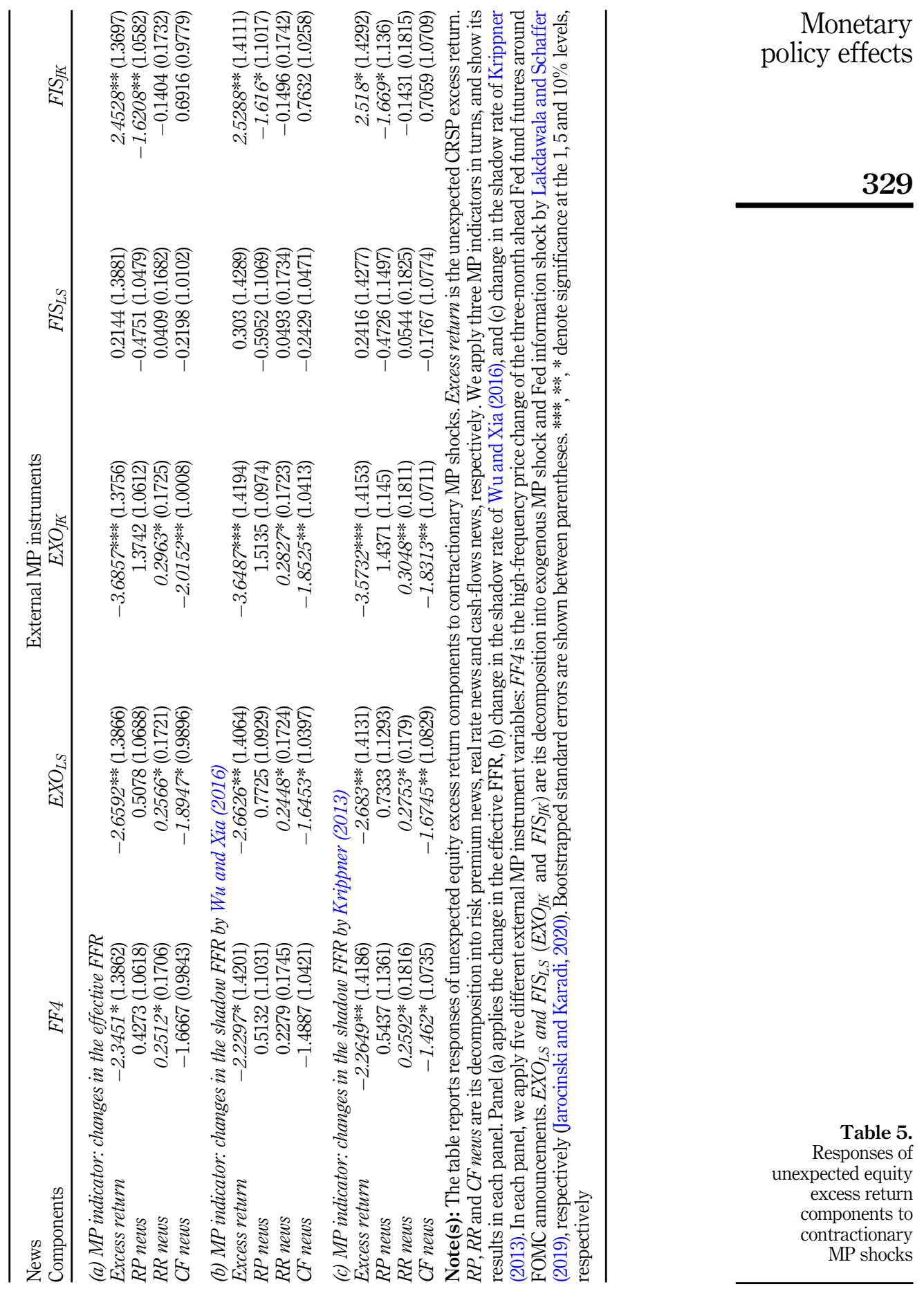


negatively. While, for central bank information shocks, although the Fed's policy increases the short rates (or, FFR), appearing as a contractionary policy, it conveys the Fed's positive outlook for the economy. This private information release by the Fed increases unexpected equity excess returns, driven mainly by decreased risk premium of firms.

\section{Conclusions}

We proposed an alternative MP shock identification approach to analyzing the MP effects on the unexpected equity excess returns news components under an SVAR setup. One can apply an MP indicator in this SVAR, which helps forecast equity excess returns in combination with their external instruments for identification. The empirical results show that when using purely exogenous MP shocks as an instrument, the unexpected changes in the excess equity returns are mostly driven by the cash-flow news component, followed by the risk premium news component. However, when using the measures of Fed information shocks as an instrument, the risk premium component decreases significantly, resulting in increases in equity excess returns.

This study mainly covers the pre-crisis period and some early parts of the recent global financial crisis (September 2008 to December 2011). To extend the research to include the entire recent crisis period (up to October 2015), it will be necessary to identify a valid MP indicator rather than using the FFRs in this study, as policy rates have been stuck at the zero lower bound. We leave this issue to future research.

\section{Notes}

1. For textbook-level content, readers may refer to Chapter 7 of Campbell et al. (1997) or Chapter 5 of Campbell (2017).

2. Patelis (1997) applied six state variables. Specifically, the state variables include the change in the federal funds rate and the portion of non-borrowed reserve growth as MP indicator variables. The other state variables are real interest rate, term spread, dividend yield and excess stock returns.

3. In Bernanke and Kuttner (2005), state variables include excess stock returns, real interest rate, change in interest rates, dividend-price ratio, term spread and relative treasury bill rate.

4. https://sites.google.com/view/jingcynthiawu/shadow-rates.

5. https://www.rbnz.govt.nz.

6. https://aeimit.weebly.com.

7. DOI: $10.1257 / \mathrm{mac} .20180090$.

\section{References}

Bernanke, B. and Kuttner, K. (2005), "What explains the stock market's reaction to federal reserve policy?”, Journal of Finance, Vol. 60, pp. 1221-1257.

Black, F. (1995), "Interest rates as options”, Journal of Finance, Vol. 50, pp. 1371-1376.

Campbell, J.Y. (2017), Financial Decisions and Markets: A Course in Asset Pricing, Princeton University Press, Princeton, New Jersey.

Campbell, J.Y. and Ammer, J. (1993), "What moves the stock and bond markets? A variance decomposition for long-term asset returns”, Journal of Finance, Vol. 48, pp. 3-37.

Campbell, J.Y., Lo, A.W. and MacKinlay, A.C. (1997), The Econometrics of Financial Markets, Princeton University Press, Princeton, New Jersey.

Gertler, M. and Karadi, P. (2015), "Monetary policy surprises, credit costs, and economic activity", American Economic Journal: Macroeconomics, Vol. 7 No. 1, pp. 44-76. 
Goto, S. and Valkanov, R. (2002), "The fed's effect on excess returns and inflation is bigger than you think", Working paper, UCLA Anderson School.

Jarocinski, M. and Karadi, P. (2020), "Deconstructing monetary policy surprises - the role of information shocks", American Economic Journal: Macroeconomics, Vol. 12 No. 2, pp. 1-43.

Krippner, L. (2013), "A tractable framework for zero-lower-bound Gaussian term structure models", Working Paper 49/2013, Centre for Applied Macroeconomic Analysis.

Lakdawala, A. and Schaffer, M. (2019), "Federal reserve private information and the stock market", Journal of Banking and Finance, Vol. 106, pp. 34-49.

Maio, P. (2013), "The 'fed model' and the predictability of stock returns", Review of Finance, Vol. 17 No. 4, pp. 1489-1533.

Mertens, K. and Ravn, M.O. (2013), "The dynamic effects of personal and corporate income tax changes in the United States", American Economic Review, Vol. 103 No. 4, pp. 1212-1247.

Patelis, A. (1997), "Stock return predictability and the role of monetary policy", Journal of Finance, Vol. 52, pp. 1951-1972.

Wu, J.C. and Xia, F.D. (2016), "Measuring the macroeconomic impact of monetary policy at the zero lower bound", Journal of Money, Credit and Banking, Vol. 48 Nos 2-3, pp. 253-291.

\section{Corresponding author}

Woon Wook Jang can be contacted at: zara2k@yonsei.ac.kr

For instructions on how to order reprints of this article, please visit our website:

www.emeraldgrouppublishing.com/licensing/reprints.htm

Or contact us for further details: permissions@emeraldinsight.com 